\title{
Improved adsorption performance of activated carbon covalently functionalised with sulphur-containing ligands in the removal of cadmium from aqueous solutions
}

\author{
M. Fronczak ${ }^{1} \cdot$ K. Pyrzyńska ${ }^{1} \cdot$ A. Bhattarai ${ }^{1} \cdot$ P. Pietrowski $^{2} \cdot$ M. Bystrzejewski $^{1}$ (D)
}

Received: 4 September 2018 / Revised: 30 October 2018 / Accepted: 2 May 2019 / Published online: 11 May 2019

(c) The Author(s) 2019

\begin{abstract}
Cadmium is a heavy metal that has high toxic potential. Biological absorption of cadmium can cause severe disease. Cadmium ions are frequently removed from the aqueous environment via adsorption. In this paper, commercially available granular activated carbon (AC) was covalently functionalised with three sulphur-containing ligands-thiodiglycol, thiourea and cysteine. The ligands were introduced in order to improve adsorption capacity for the removal of cadmium ions from aqueous solutions. The AC functionalised with cysteine and thiourea had twice the adsorption capacity of Cd(II) than the pristine AC. The introduction of sulphur-containing ligands also improved the adsorption kinetics, i.e. the adsorption kinetic rates were ca. 2-10 times higher than the pristine AC. This enhancement of the adsorption performance was systematically studied in terms of morphology, texture, structural features, the content of sulphur-containing ligands and surface chemistry.
\end{abstract}

Keywords Activated carbon $\cdot$ Functionalisation $\cdot$ Cadmium $\cdot$ Adsorption kinetics

\section{Introduction}

Cadmium is one of the most toxic elements, and can seriously affect human health. The dispersion of cadmium into the environment results from industrial processes, domestic activities, agricultural practices (e.g. fertilisers), the use of $\mathrm{Cd}(\mathrm{II})$-containing goods and the disposal of waste (Sukreeyapongse et al. 2002). Inhalation of cadmium-containing fumes can cause various severe diseases, including pneumonitis and pulmonary oedema, and can even result death (Fernandez et al. 1996). Moreover, from the epidemiological studies, this element is known to be carcinogenic,

Editorial responsibility: Necip Atar.

Electronic supplementary material The online version of this article (https://doi.org/10.1007/s13762-019-02398-0) contains supplementary material, which is available to authorized users.

M. Bystrzejewski

mibys@chem.uw.edu.pl

1 Department of Chemistry, University of Warsaw, 02-093 Warsaw, Poland

2 Dream Consulting Piotr P. Pietrowski, 95-010 Dobra-Nowiny, Poland and exposure to it should be limited to the lowest possible levels (Hartwig 2013). In addition, the toxicity of has a cumulative character because its biological half-life in the human body is between 10 and 30 years. Most absorbed $\mathrm{Cd}$ (II) cadmium accumulates in the liver and kidneys (Lind et al. 1997).

The removal of $\mathrm{Cd}(\mathrm{II})$ from aqueous systems is generally realised via different treatment technologies, namely adsorption (Attar et al. 2018; Izidoro et al. 2013; Huang et al. 2013), reverse osmosis (Kheriji et al. 2015; Pirsaheb et al. 2017), nanofiltration (Gao et al. 2016; Liu et al. 2016; Saljoughi and Mousavi 2013) and precipitation (Islamoglu et al. 2006; Tan et al. 2013).

Activated carbon (AC) is commonly used in the adsorptive removal of various heavy metals from aqueous solutions, including Cd(II) (Youssef et al. 2004; Huang et al. 2007; Machida et al. 2012). Its adsorption properties primarily depend on surface chemistry features, while their textural properties are of minor importance (Pyrzyńska 2010). AC is routinely subjected to oxidisation in order to introduce new surface acidic functional groups, and to enhance their adsorption properties. Metal uptake occurs via non-covalent electrostatic interactions between heavy metal cations and negatively charged surface functional groups (Radovic et al. 2001). The introduction of surface oxygen-containing acidic 
groups obviously improves the adsorption capacity (Rodríguez-Estupiñana et al. 2013); however, selectivity towards a specific heavy metal ion is only moderate (Faur-Brasquet et al. 2002).

This work is focused on the comparison of three sulphurcontaining ligands (which are covalently attached to AC) used in the removal of $\mathrm{Cd}$ (II) ions from aqueous solutions. It is known that $\mathrm{Cd}$ (II) forms stable and strong complexes with sulphur-containing molecules, e.g. cysteine (Jalihenvand et al. 2009) and thiourea (El-Bahy et al. 2003). Recent works have demonstrated that even zero-valent sulphur nanoparticles also have the potential to bind Cd(II) ions (Ghanemi et al. 2011). More complex molecules also form stable complexes with $\mathrm{Cd}(\mathrm{II})$. For example, Yola et al. demonstrated that glassy carbon functionalised with 2-thiolbenzimidazole selectively reacts with $\mathrm{Cd}(\mathrm{II})$, and can be used for the construction of electrochemical sensors of Cd(II) ions in human plasma (Lütfi Yola et al. 2014). It has also been shown that calixarene and $p$-aminophenol moieties have a high affinity for Cd(II) (Göde et al. 2017; Gupta et al. 2013). Cadmium ions also form stable complexes (even at low concentrations) with sulfisoxazole. In this case, Cd(II) ions do not directly interact with the sulphur moiety, but form a complex with sulfisoxazole via a coordinative bond with the oxazole group.

\section{Materials and methods}

\section{Materials}

Activated carbon (particle size between 0.3 and $0.5 \mathrm{~mm}$ ) was purchased from FLUKA, and used as received. Before any chemical treatment or analysis, each sample of $\mathrm{AC}$ was thoroughly dried in an oven (typically $2 \mathrm{~h}, 420-430 \mathrm{~K}$ ). The mass loss during drying was between 5 and $7 \%$. Dimethylformamide (DMF), thionyl chloride, triethylamine, $\mathrm{HNO}_{3}$, thiodiglycol, thiourea and L-cysteine ethyl ester hydrochloride were purchased from Sigma. All reagents had a purity of greater than $98.5 \%$. The solvents were dried before use.

\section{Chemical functionalisation}

The general functionalisation scheme is shown in Fig. 1. First, the pristine $\mathrm{AC}$ was subjected to $\mathrm{HNO}_{3}$ treatment in order to introduce surface functional groups. A sample of pristine $\mathrm{AC}(5 \mathrm{~g})$ was added to $300 \mathrm{~mL}$ of $8 \mathrm{M} \mathrm{HNO}_{3}$ and boiled for $2 \mathrm{~h}$. Then, the material was rinsed with distilled water until the $\mathrm{pH}$ was greater than 5 , and was dried in air at $380 \mathrm{~K}$. The surface-oxidised AC was labelled AC-COOH. Three sulphur-containing ligands (thiodiglycol, thiourea and L-cysteine) were covalently attached to the surface of the oxidised AC via ester (thiodiglycol) or amide bonds (thiourea and cysteine). First, the carboxylic groups on oxidised AC were converted to acyl chlorides. In brief, $1 \mathrm{~g}$ of the dried $\mathrm{AC}-\mathrm{COOH}$ was added to a mixture of $100 \mathrm{~mL}$ thionyl chloride and $10 \mathrm{~mL} \mathrm{DMF}$, and then refluxed for $10 \mathrm{~h}$. Next, the organic part was evaporated under reduced pressure, and the resultant $\mathrm{AC}-\mathrm{COCl}$ was dried at $360 \mathrm{~K}$ under an Ar atmosphere.

The obtained AC-COCl was used as the reagent for subsequent grafting with thiourea or L-cysteine. The sulphurcontaining ligand (thiourea or L-cysteine ethyl ester hydrochloride, $2 \mathrm{~g}$ ) was dissolved in anhydrous DMF with a small amount of triethylamine $(10 \mathrm{~mL})$. This solution was dripped into a bulb in which AC-COCl was present. Then, the mixture was magnetically stirred under Ar at $330 \mathrm{~K}$ for $24 \mathrm{~h}$. Next, the product obtained from the reaction with L-cysteine ethyl ester hydrochloride was treated with $100 \mathrm{~mL} 2 \mathrm{M}$ $\mathrm{HCl}$ for $15 \mathrm{~h}$ at $330 \mathrm{~K}$. This treatment was necessary in order to hydrolyse the ester bond. The functionalised AC with L-cysteine and thiourea was labelled AC-cysteine and AC-thiourea, respectively. After functionalisation, the ACcysteine and $\mathrm{AC}$-thiourea materials were rinsed in an excess of acetone, and dried in air at $380 \mathrm{~K}$.

The functionalisation of AC with thiodiglycol was as follows. Two grams of AC-COOH, $20 \mathrm{~mL}$ of thiodiglycol and $4 \mathrm{~mL}$ of concentrated sulphuric acid were added to $100 \mathrm{~mL}$ DMF. The obtained suspension was refluxed for $10 \mathrm{~h}$, and then filtered and rinsed with an excess of acetone through a filter paper. Next, the sample was dried in air at $380 \mathrm{~K}$.

In addition, the pristine $\mathrm{AC}$ was annealed in a tube oven at $1273 \mathrm{~K}$ for $1 \mathrm{~h}$ under an Ar flow. This material was labelled AC-1273 K.

\section{Characterization}

The morphology of the activated carbons was studied by scanning electron microscopy (SEM, Zeiss Merlin). The infrared spectra were acquired using a Shimadzu 8201 instrument with a spectral resolution of $2 \mathrm{~cm}^{-1}$. The studied carbon sample (ca. $1.0-1.5 \mathrm{mg}$ ) was ground in an agate mortar and mixed with $\mathrm{KBr}(300 \mathrm{mg}$ ), and subsequently pressed into a pellet. Low-temperature nitrogen adsorption was carried out at $77 \mathrm{~K}$ using an Autosorb iQ analyser. The samples were degassed at $420 \mathrm{~K}$ under a vacuum $\left(10^{-5}\right.$ mbar $)$ prior to the measurements. Thermogravimetric analyses were carried out using a TA Q-50 instrument under nitrogen, with a heating rate of $5 \mathrm{~K} \mathrm{~min}^{-1}$. The point of zero charge was measured by the mass titration method (Noh and Shwarz 1990). The $\mathrm{pH}$ of the starting $0.01 \mathrm{M} \mathrm{NaCl}$ solution $(30 \mathrm{~mL})$ was adjusted to 10 by adding small volumes of $0.1 \mathrm{M} \mathrm{NaOH}$ and $\mathrm{HCl}$. Then, the desired amount of carbon sample was added, and the $\mathrm{pH}$ was measured after it reached the equilibrium value (typically after $30 \mathrm{~min}$ ). The suspension was 


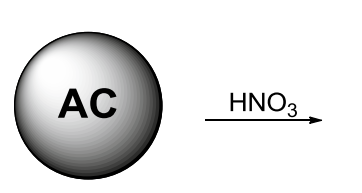<smiles>O=C(O)C1CCC(C(=O)O)CC(C(=O)O)CCC(C(=O)O)C1</smiles><smiles>O=C(Cl)c1ccc(C(=O)Cl)cc(C(=O)Cl)cc(C(=O)Cl)cc1</smiles><smiles>NC(=S)NC1CCC(C(=O)Cl)CC(C(=O)Cl)CC(C(=O)Cl)CC1</smiles><smiles>NC(=S)NC(=O)c1ccc(C(=O)NC(N)=S)ccc(C(=O)NC(N)=S)c(C(=O)NC(N)=S)cc1</smiles><smiles></smiles><smiles>O=C(OCC(O)CS)C1CCC(C(=O)OCC(O)CS)CCC(C(=O)OCC(O)CS)CCC(C(=O)OCC(O)CS)CC1</smiles><smiles>O=C(Cl)C1=CCC(C(=O)Cl)CC(C(=O)Cl)CC(C(=O)Cl)CC1</smiles><smiles>CCOC(=O)[C@@H](CS)NCl</smiles><smiles></smiles><smiles>O=C(NC(CS)C(=O)O)C1CCC(C(=O)NC(CS)C(=O)O)CC(C(=O)NC(CS)C(=O)O)CC(C(=O)NC(CS)C(=O)O)CC1</smiles>

Fig. 1 Modification of activated carbons functionalised with sulphur-containing ligands

continuously purged with Ar to eliminate interference from ambient $\mathrm{CO}_{2}$, if any. The mass titration curves are shown in Figures S1-S6 (Supplementary Data).

The content of the surface functional groups was evaluated by the Boehm titration method (Boehm 2002). About $300 \mathrm{mg}$ of the studied carbon material (the mass was precisely monitored) was placed in a vial containing $50 \mathrm{~mL}$ of $0.05 \mathrm{M}$ base $\left(\mathrm{NaOH}, \mathrm{Na}_{2} \mathrm{CO}_{3}\right.$ and $\left.\mathrm{NaHCO}_{3}\right)$. The vials were tightly sealed with parafilm tape and shaken for $24 \mathrm{~h}$. Then, a $5 \mathrm{~mL}$ aliquot of each filtrate was titrated with $0.05 \mathrm{M} \mathrm{HCl}$ using a Metrohm Titrando automatic titrator. The aliquots were bubbled with $\mathrm{Ar}$ to prevent absorption of ambient $\mathrm{CO}_{2}$.
The titrations were done in triplicate. The content of acidic functional groups was calculated under the assumption that: the $\mathrm{NaOH}$ neutralised the carboxylic, phenolic and lactonic groups; the $\mathrm{Na}_{2} \mathrm{CO}_{3}$ reacted exclusively with the carboxylic and lactonic groups; and the $\mathrm{NaHCO}_{3}$ neutralised the carboxylic groups only. The ash content was evaluated from the thermogravimetric curve (burning in an $\mathrm{O}_{2}$ atmosphere at a heating rate of $5 \mathrm{~K} \mathrm{~min}^{-1}$ ). 


\section{Adsorption of Cd(II)}

The adsorption of $\mathrm{Cd}(\mathrm{II})$ was investigated at $\mathrm{pH} 7$ (ammonium acetate solution) at constant temperature $(298 \pm 1 \mathrm{~K})$. The stock solution of cadmium nitrate (1000 mg/L) was purchased from Merck. For the adsorption studies, a $50 \mathrm{mg}$ sample of carbon material was added to a $10 \mathrm{~mL}$ solution of $\mathrm{Cd}(\mathrm{II})$ (initial concentration between 2 and $100 \mathrm{mg} / \mathrm{L}$ ), with subsequent vigorous shaking for $4 \mathrm{~h}$. Then, the carbon adsorbent was filtered onto a paper filter, and the concentration of $\mathrm{Cd}(\mathrm{II})$ in the recovered solution was measured via an atomic absorption spectrometer equipped with a flame atomisation probe (PerkinElmer 3110). The adsorption kinetics studies were carried out as follows. Samples containing $50 \mathrm{mg}$ of the studied material were added to $50 \mathrm{~mL}$ of the solution $(20 \mathrm{mg} / \mathrm{L}, \mathrm{pH}=7)$ of $\mathrm{Cd}(\mathrm{II})$. The suspensions were mechanically shaken for 5-240 min. The adsorption capacity for each contact time was determined by individual testing. The operational parameters of the measurements are shown in the Supplementary Data.

\section{Results and discussion}

\section{Morphology}

The SEM images of the studied activated carbons are shown in Fig. 2. It can be seen from the micrographs that the external surface of the pristine AC has cracks, holes and crevices in it. Moreover, there are some fine, brighter particles on the surface. These particles are likely the ash fraction, which usually accompanies commercial AC. The annealed AC sample has a similar morphology; however, the number of cracks and holes is lower. This finding points to a lower macroporosity in this material. The AC-COOH sample has a completely different surface morphology. The cracks, holes and crevices are not present, and this observation suggests that AC-COOH should have substantially reduced porosity.
Fig. 2 SEM images of activated carbons
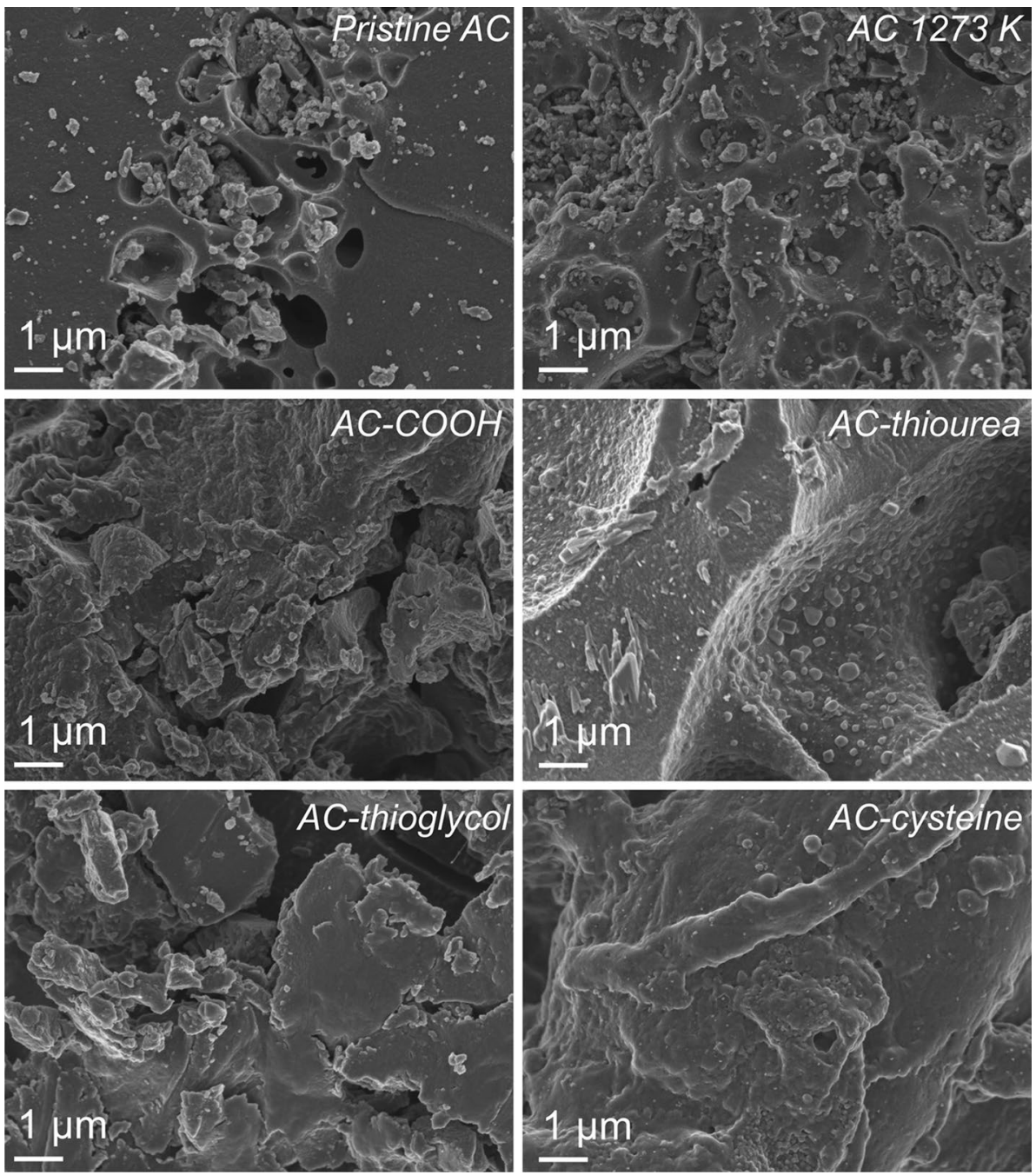


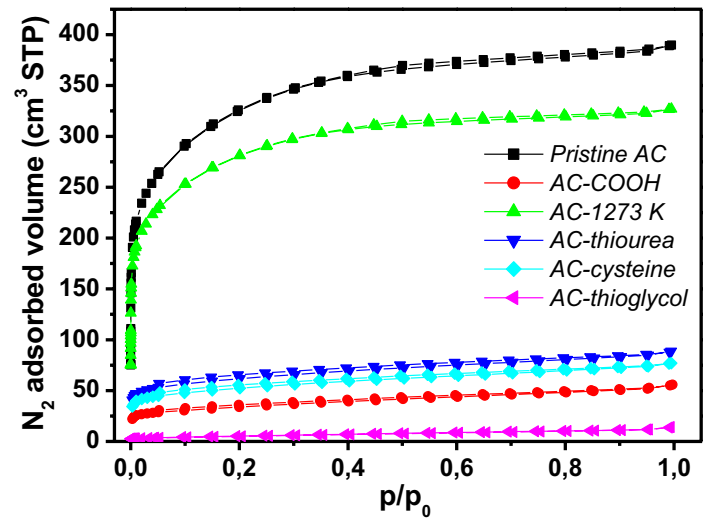

Fig. 3 Nitrogen adsorption-desorption isotherms of activated carbons

Table 1 Textural parameters of studied activated carbons

\begin{tabular}{|c|c|c|c|c|}
\hline $\begin{array}{l}\text { Activated } \\
\text { carbon }\end{array}$ & $\begin{array}{l}\text { Total pore } \\
\text { volume } \\
\left(\mathrm{cm}^{3} / \mathrm{g}\right)\end{array}$ & $\begin{array}{l}\text { Micropore } \\
\text { volume } \\
\left(\mathrm{cm}^{3} / \mathrm{g}\right)\end{array}$ & $\begin{array}{l}\text { Mesopore } \\
\text { volume } \\
\left(\mathrm{cm}^{3} / \mathrm{g}\right)\end{array}$ & $\begin{array}{l}\text { Surface } \\
\text { area } \\
\left(\mathrm{m}^{2} / \mathrm{g}\right)\end{array}$ \\
\hline AC-pristine & 0.603 & 0.24 & 0.32 & 1083 \\
\hline AC $1273 \mathrm{~K}$ & 0.505 & 0.17 & 0.30 & 944 \\
\hline AC-COOH & 0.086 & 0.03 & 0.05 & 119 \\
\hline AC-thiourea & 0.137 & 0.07 & 0.05 & 220 \\
\hline $\begin{array}{l}\text { AC-thiodi- } \\
\text { glycol }\end{array}$ & 0.021 & $<0.01$ & 0.02 & 14 \\
\hline AC-cysteine & 0.119 & 0.05 & 0.04 & 187 \\
\hline
\end{tabular}

Moreover, ash particles are also not seen. This finding suggests that the ash was irreversibly dissolved during the treatment in $\mathrm{HNO}_{3}$. The activated carbons functionalised with sulphur-containing ligands have similar morphological features to those of the AC-COOH sample. Their surfaces are free of cracks, and possess a 'glassy' appearance (especially AC-thiodiglycol and AC-cysteine). This observation likely suggests that sulphur-containing ligands form a film-like structure and that they are located primarily on the surface of the AC.

\section{Textural properties}

Figure 3 shows the nitrogen adsorption-desorption isotherms. All curves are of type I, according to the IUPAC classification scheme (Balbuena and Gubbins 1993). A rough comparison of the curves indicates that only pristine and annealed ACs are microporous materials, with a relatively high pore volume and large surface area. The textural parameters (total pore volume, micro- and mesopore volume and specific surface area) were evaluated using a DFT model (Table 1). The pristine AC had the largest surface area, which resulted from the highest micropore volume. The relative proportion of micropores in this material exceeded $53 \%$. The AC sample after annealing had a decreased surface area, by ca. $17 \%$. This is typical behaviour for annealed AC, and has been reported previously (Biniak et al. 2010). The $\mathrm{HNO}_{3}$ treatment dramatically decreased both micropore volume and surface area. These observations confirm the predictions obtained from analysis of the SEM images. This result is in general agreement with those of previous studies (Moreno-Castilla et al. 2000). This finding suggests that the sites in which the micropores are located were primarily etched and gasified during $\mathrm{HNO}_{3}$ treatment. In fact, these sites have greater structural disorder than the bulk carbon material (Harris et al. 2008), and primarily undergo chemical degradation and gasification. The carbons functionalised with sulphur-containing ligands have different textural properties than the AC-COOH sample. There is no clear relationship between the ligand structure and the resultant micropore volume or surface area. In the case of AC-thiodiglycol, the surface area was 15 times lower than the carbon oxidised in $\mathrm{HNO}_{3}$. The porosity of the AC-functionalised cysteine and thiourea is on a comparable level to that of the AC-COOH material.

\section{Elemental composition and surface chemistry}

The elemental composition is shown in Table 2. The pristine and annealed ACs have a similar composition, and the carbon content exceeds $85 \%$. The oxidation in $\mathrm{HNO}_{3}$ substantially decreased the carbon content, with a simultaneous
Table 2 Elemental composition (wt \%), ash content (wt \%) and content of sulphur-containing ligand (wt\%)

\begin{tabular}{llllllll}
\hline Activated carbon & $\mathrm{C}$ & $\mathrm{H}$ & $\mathrm{N}$ & $\mathrm{S}$ & $\mathrm{O}^{*}$ & Ash & $\begin{array}{c}\text { Content } \\
\text { of ligand }\end{array}$ \\
\hline AC-pristine & 86.8 & 2.4 & 1.4 & 0.4 & 2.8 & 6.2 & $\mathrm{NA}$ \\
AC 1273 K & 85.6 & 2.5 & 1.4 & 0.3 & 3.7 & 6.5 & NA \\
AC-COOH & 53.5 & 2.9 & 2.0 & 0.2 & 39.0 & 2.4 & NA \\
AC-thiourea & 56.8 & 3.0 & 3.7 & 5.3 & 29.2 & 2.0 & 14.7 \\
AC-thiodiglycol & 60.9 & 3.6 & 2.3 & 3.8 & 27.3 & 2.1 & 12.6 \\
AC-cysteine & 58.3 & 3.2 & 2.7 & 2.3 & 31.5 & 2.0 & 8.8 \\
\hline
\end{tabular}

*Oxygen content by difference 
increase in the oxygen content. This effect is caused by the presence of surface acidic groups, introduced during the treatment in $\mathrm{HNO}_{3}$. Importantly, the ash content decreased by more than twice in comparison with the pristine AC. This shows that the ash has a mineral character, and can be removed during treatment in $\mathrm{HNO}_{3}$. The functionalisation with sulphur-containing ligands resulted in an increase in the carbon content. The increase in carbon content of the functionalised ACs changed in the following order: ACthiodiglycol $>$ AC-cysteine $>$ AC-thiourea, and is in perfect agreement with the mole fraction of carbon in the respective sulphur-containing ligands $(0.39>0.29>0.16)$. This finding, along with the observed increase in sulphur content (by 6-13 times) is clear evidence that the functionalisation was successful. The increase in nitrogen content in AC-cysteine and AC-thiourea also points to the sulphur-containing ligands being attached to the AC surface.

The ligand content was evaluated by comparing the mole fraction of sulphur in the ligand and the sulphur content in the functionalised carbons. The content of the ligands varied between 8.8 and $14.7 \mathrm{wt} \%$ (Table 2). Thermogravimetric analysis (TGA) was also performed in order to verify the content of the attached ligands (Fig. 4). The analysis was carried out under a nitrogen atmosphere in order to eliminate possible oxidation processes. For a proper interpretation of the TGA curves, one has to be aware that an increase in temperature initiates the decomposition/pyrolysis of the ligands and surface acidic groups, which are present on the AC surface. The observed mass loss for the pristine AC was only $3 \%$. The functionalised ACs showed markedly higher mass losses, and their values generally following the trend for the ligand content evaluated by elemental analysis. It should be highlighted that the observed mass loss concerns the decomposition of both (1) sulphur-containing ligands bound to the surface, and (2) remnant surface acidic groups, which were not used in the binding of the ligands. Therefore, the curves

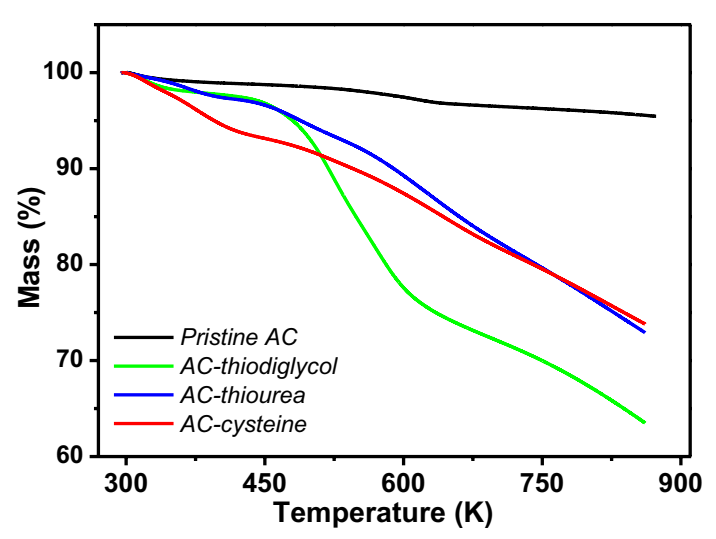

Fig. 4 Thermogravimetric curves of pristine and functionalised activated carbons for AC-cysteine and AC-thiourea look similar, apart from the distinct contents evaluated by elemental analysis.

Further details were obtained from FT-IR spectra (Fig. 5). The obtained spectra had very strong backgrounds, which originated from continuous absorption and scattering from the black grains of the AC samples. The specific bands of the respective functional groups had very low intensity and, therefore, the spectra are presented in arbitrary absorbance units (after subtraction of the background). Obviously, this procedure is inadequate for providing quantitative compositions of the functionalised carbons; however, it is possible to deduce qualitative data and evaluate surface chemistry features from the FT-IR spectra.

The spectrum of pristine $\mathrm{AC}$ has three characteristic bands, located at $1550 \mathrm{~cm}^{-1}, 1285 \mathrm{~cm}^{-1}$ and $1100 \mathrm{~cm}^{-1}$. A band at $3200-3500 \mathrm{~cm}^{-1}$ was observed in all samples, and originates from adsorbed moisture. Its diagnostic utility is of marginal importance and the changes in this spectral feature during functionalisation were not analysed. The feature at $1550 \mathrm{~cm}^{-1}$ is typical for carbon materials, and results from conjugated stretching vibrations in aromatic $\mathrm{C}-\mathrm{C}$ bonds (Pakuła et al. 2005). The bands at $1285 \mathrm{~cm}^{-1}$ and $1100 \mathrm{~cm}^{-1}$ can be attributed to the stretching vibrations of $\mathrm{C}-\mathrm{O}$ moiety in various aliphatic functionalities (ester and ether). The spectrum of annealed AC had the same features as the pristine AC. Note that $\mathrm{AC}$ always contains some amount of oxygen, and the presence of oxygen moieties was an expected finding.

The spectrum of the AC-COOH sample revealed two strong features $\left(1195 \mathrm{~cm}^{-1}\right.$ and $\left.1710 \mathrm{~cm}^{-1}\right)$, which are not present in the pristine and annealed AC. Both these bands correspond to the stretching vibrations of $\mathrm{C}-\mathrm{O}$ and $\mathrm{C}=\mathrm{O}$ bonds in the carboxylic functional group. This observation proves that the oxidation process was successful, and that surface acidic groups were introduced onto the surface of the AC. The ACs functionalised with sulphur-containing ligands had an intensive band at $1540-1550 \mathrm{~cm}^{-1}$, which originated from the $\mathrm{C}=\mathrm{C}$ stretching vibration. There were two sharp bands, located at $1120 \mathrm{~cm}^{-1}$ and $1225 \mathrm{~cm}^{-1}$, in the ACthiourea sample. The first feature had a frequency typical for the $\mathrm{C}=\mathrm{S}$ stretching vibration (Lin-Vien et al. 1991). The second band may be attributable to $\mathrm{C}-\mathrm{O}$ vibrations in the free carboxylic groups, i.e. those not used in the conjugation of thiourea molecules. On the other hand, this band could also correspond to $\mathrm{C}-\mathrm{N}$ symmetric modes (which are typical for the thiourea molecule). Importantly, the $\mathrm{C}=\mathrm{O}$ stretching vibration was downshifted to $1700 \mathrm{~cm}^{-1}$ (in comparison with the AC-COOH sample), and this observation directly proves that the amide bond between the carboxylic groups on the carbon surface and the amine groups in thiourea was formed. The spectrum of AC-thiodiglycol had several strong bands, i.e. $1115 \mathrm{~cm}^{-1}, 1210 \mathrm{~cm}^{-1}, 1710 \mathrm{~cm}^{-1}$ and $2900 \mathrm{~cm}^{-1}$. The last band originates from $\mathrm{C}-\mathrm{H}$ stretching vibrations. The 

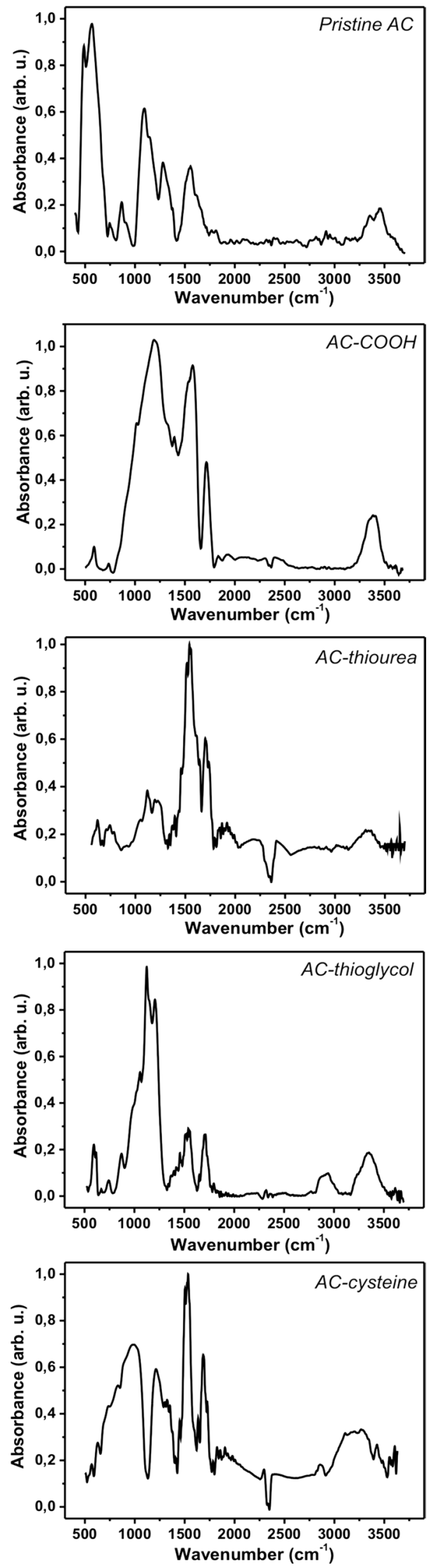

Fig. 5 FT-IR spectra of activated carbons former two bands are associated with $\mathrm{C}-\mathrm{O}$ stretching modes. The band located at $1710 \mathrm{~cm}^{-1}$ is obviously from the symmetric $\mathrm{C}-\mathrm{O}$ vibrations in the ester moiety. There was also a band located at $740 \mathrm{~cm}^{-1}$, which can be ascribed to the $\mathrm{C}-\mathrm{S}$ stretching vibration. This spectral feature, even in the case of pure thiodiglycol and other compounds containing $\mathrm{C}-\mathrm{S}$ moieties, was of relatively weak intensity (Socrates 2001).

The following bands appeared on the spectrum of the AC-cysteine sample: $1215 \mathrm{~cm}^{-1}, 1330 \mathrm{~cm}^{-1}, 1690 \mathrm{~cm}^{-1}$ and $2900 \mathrm{~cm}^{-1}$. The first and last features originate from $\mathrm{C}-\mathrm{O}$ and $\mathrm{C}-\mathrm{H}$ stretching vibrations, respectively. The band at $1330 \mathrm{~cm}^{-1}$ can be attributed to the $\mathrm{C}-\mathrm{N}$ stretching mode. The spectral feature located at $1690 \mathrm{~cm}^{-1}$ originates from the $\mathrm{C}=\mathrm{O}$ moiety in the amide group. There was also a weak band at $3430 \mathrm{~cm}^{-1}$, and this feature was distinguished from the broad $\mathrm{O}-\mathrm{H}$ band. This band is likely due to N-H stretching vibrations. The band from the $\mathrm{S}-\mathrm{H}$ functionality (ca. $2600 \mathrm{~cm}^{-1}$ ) was absent. This observation suggests that the cysteine molecule was bound to the surface of the AC via both amide and thioester bonds. Another explanation for this absence may be related to the fact that the $\mathrm{S}-\mathrm{H}$ mode, even in the case of pure cysteine, has a very low intensity (Figure $\mathrm{S} 1$ ). In other words, even if this functionality is present, it has too low intensity to be discriminated from the background. To conclude, analysis of the FT-IR spectra clearly indicated that the surface of the AC was functionalised, and the observed bands undoubtedly agree with the structural units of the covalently attached surface-containing ligands.

The point of zero charge and the results of the Boehm titration are presented in Table 3. (The mass titration curves are shown in Figures S1-S6.) The pristine AC had weak acidic properties, because its point of zero charge is 6.44 . Its total surface acidity did not exceed $0.60 \mathrm{mmol} / \mathrm{g}$, and the relative content of carboxylic groups was $25 \%$. (These functional groups have a higher dissociation constant than the lactonic and phenolic groups.) The annealing process largely reduced the total acidity (by more than one order of magnitude) and increased the $\mathrm{pH}_{\mathrm{ZC}}$ to 6.82. The $\mathrm{AC}$ oxidised in $\mathrm{HNO}_{3}$ had a substantially higher content of surface acidic groups, and its point of zero charge was downshifted to 4.15. Interestingly, the relative content of carboxylic groups in the AC-COOH sample was ca. 56\%. The ACs functionalised with sulphur-containing ligands had a slightly lower surface acidity. This is an expected result because both thiourea and thioglycol are molecules that do not donate any groups that can undergo the dissociation process and increase the acidity.

In the case of $\mathrm{AC}$ functionalised with cysteine, the reduction in surface acidity was the smallest. This is because the cysteine molecule, after conjugation to $\mathrm{AC}$, donates an extra carboxylic group. As a consequence, the point of zero charge in the AC-cysteine sample was lower than in the AC functionalised with two other sulphur-containing ligands. The 
Table 3 Content of surface acidic groups and point of zero charge $\left(\mathrm{pH}_{\mathrm{ZC}}\right)$ for studied activated carbons

\begin{tabular}{llllll}
\hline Activated carbon & $\begin{array}{l}\text { Total content of acidic } \\
\text { groups (mmol/g) }\end{array}$ & $\begin{array}{l}\text { Carboxylic } \\
\text { groups (mmol/g) }\end{array}$ & $\begin{array}{l}\text { Lactonic } \\
\text { groups } \\
(\mathrm{mmol} / \mathrm{g})\end{array}$ & $\begin{array}{l}\text { Phenolic } \\
\text { groups } \\
(\mathrm{mmol} / \mathrm{g})\end{array}$ & $\mathrm{pH}_{\mathrm{ZC}}$ \\
\hline AC-pristine & 0.60 & 0.15 & 0.20 & 0.25 & 6.44 \\
AC 1273 K & 0.05 & $<0.01$ & 0.01 & 0.03 & 6.82 \\
AC-COOH & 5.60 & 3.16 & 0.88 & 1.56 & 4.15 \\
AC-thiourea & 4.29 & 2.17 & 0.67 & 1.45 & 4.54 \\
AC-thiodiglycol & 3.22 & 1.59 & 0.69 & 0.94 & 4.96 \\
AC-cysteine & 4.32 & 2.23 & 0.72 & 1.37 & 4.48 \\
\hline
\end{tabular}

largest reduction in surface acidity (by nearly twice) was observed in AC-thiodiglycol. In this sample, the low content of acidic groups was accompanied by the highest $\mathrm{pH}_{\mathrm{ZC}}$. The content of thiodiglycol ligands in the AC-thioglycol sample $(12.6 \%)$ was comparable to that in the AC-thiourea material (14.7\%); however, the reduction in surface acidity for the AC-thioglycol sample was much larger. Hence, it is highly likely that thiodiglycol molecules (which contain two $\mathrm{O}-\mathrm{H}$ groups) are cross-linked onto the surface of AC. Another interesting finding was that the relative content of carboxylic groups in AC-cysteine, AC-thioglycol and AC-thiourea was between 49 and $52 \%$, and this value was of the same order as in the $\mathrm{AC}-\mathrm{COOH}$ sample. The same observations were made for the relative content of lactonic and phenolic groups in sulphur-functionalised carbons and $\mathrm{AC}-\mathrm{COOH}$ material.

\section{Adsorption of $\mathrm{Cd}(\mathrm{II})$}

Figure 6 shows the adsorption isotherms of $\mathrm{Cd}$ (II) onto the studied ACs. A brief look at the isotherms indicates that the pristine and annealed activated carbons exhibited different adsorption behaviours than the surface-functionalised materials. The adsorption isotherm for the pristine $\mathrm{AC}$ and AC-1273 was convex at a low equilibrium concentration [isotherm type V in the IUPAC classification (Balbuena and Gubbins 1993)]. This effect was more pronounced in the AC-1273 sample. The occurrence of the convex isotherm points to cooperative adsorption, i.e. at a low concentration range, the interaction between $\mathrm{Cd}(\mathrm{II})$ and water molecules is stronger than the forces that are responsible for the electrostatic attraction to the surface of the AC. The isotherms of the surface-functionalised carbons were of type I, which is typical for strong interactions between the solute and the adsorbent surface. The monolayer in the pristine AC was completed at the equilibrium concentration of $20 \mathrm{mg} / \mathrm{L}$. The adsorption of $\mathrm{Cd}(\mathrm{II})$ onto $\mathrm{AC}-\mathrm{COOH}$ occurred in a different manner, i.e. the isotherm reached equilibrium at a very low solute concentration (ca. $8-10 \mathrm{mg} / \mathrm{L}$ ). This points to very strong interactions between the solute and the surface of the carbon adsorbent. In the case of $\mathrm{AC}$ functionalised
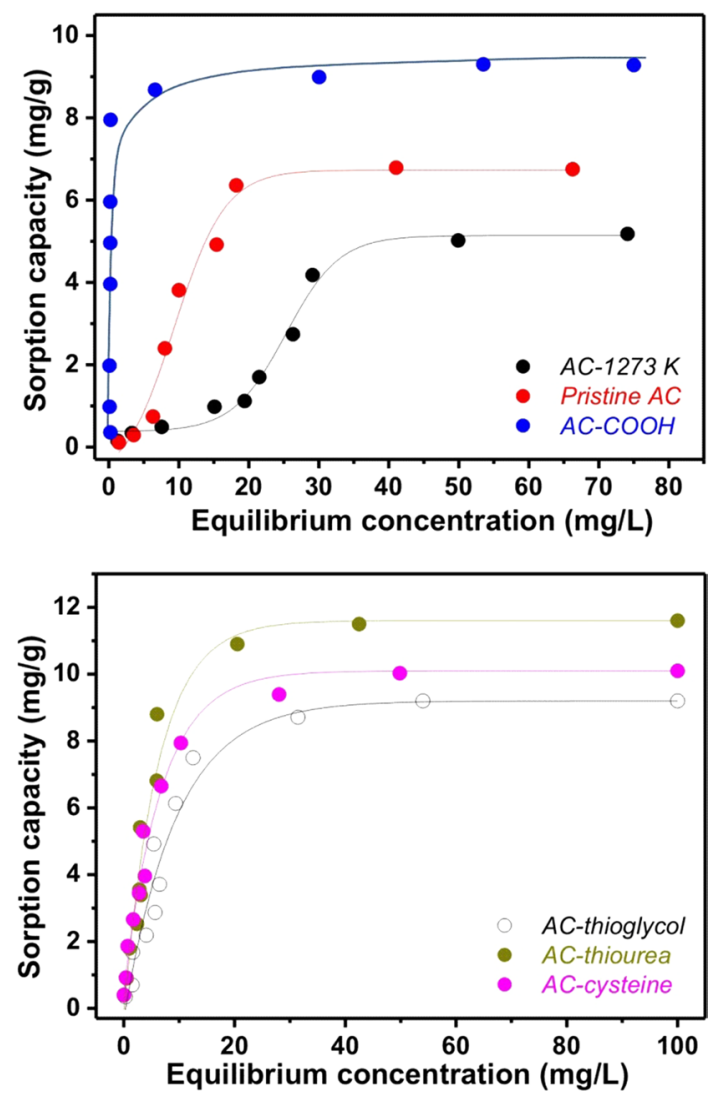

Fig. 6 Adsorption isotherms of Cd(II) onto activated carbons. Solid lines are only to guide the eye

with sulphur-containing ligands, the completion of the monolayer requires higher activity of the solute. The equilibrium was reached when the concentration of $\mathrm{Cd}$ (II) exceeded 20-30 mg/L.

The adsorption data from surface-functionalised carbons were nonlinearly fitted using the Langmuir isotherm equation. The calculated maximum adsorption capacity and the affinity constants $\left(K_{\mathrm{L}}\right)$ are summarised in Table 4 . (The results of fitting are shown in Figures S8-S11.) The adsorption capacities for the pristine and annealed carbons were taken directly from the isotherms because the experimental 
Table 4 Content of sulphurcontaining ligand, adsorption capacity of Cd(II), Langmuir adsorption affinity constants (K) and adsorption kinetics rates $\left(\mathrm{k}_{2}\right)$ for studied activated carbons

\begin{tabular}{lllll}
\hline Activated carbon & $\begin{array}{l}\text { Content of ligand } \\
(\mathrm{wt} \%)\end{array}$ & $\begin{array}{l}\text { Adsorption capacity } \\
\Gamma_{\max }(\mathrm{mg} / \mathrm{g})\end{array}$ & $K(\mathrm{~L} / \mathrm{mg})$ & $\begin{array}{l}k_{2} \\
\left(\mathrm{~min}^{-1} \mathrm{mg}^{-1} \mathrm{~g}\right)\end{array}$ \\
\hline AC-pristine & $\mathrm{NA}$ & $6.19^{*}$ & $\mathrm{NA}$ & 0.144 \\
AC $1273 \mathrm{~K}$ & $\mathrm{NA}$ & $4.52^{*}$ & $\mathrm{NA}$ & 0.141 \\
AC-COOH & $\mathrm{NA}$ & 9.50 & 1.45 & 0.152 \\
AC-thiourea & 14.7 & 12.10 & 0.32 & 0.368 \\
AC-thiodiglycol & 12.6 & 10.20 & 0.15 & 0.310 \\
AC-cysteine & 8.8 & 10.65 & 0.26 & 1.860 \\
\hline
\end{tabular}

*Adsorption capacity taken directly from the plateau on the adsorption isotherm data could not be directly fitted using the Langmuir equation. The maximum adsorption capacity changed in the following order: AC-thiourea $>$ AC-cysteine $>$ AC-thiodiglycol $>$ AC-COOH $>$ AC-pristine $>$ AC-1273 K. It is clear that the attachment of sulphur-containing ligands increased the uptake of $\mathrm{Cd}(\mathrm{II})$ ions. The greatest improvement to the adsorption capacity was observed in the AC-thiourea sample and, in this case, the adsorption capacity increased two times (from 6.19 to $12.10 \mathrm{mg} / \mathrm{g}$ ). In comparison with the $\mathrm{AC}$ treated in $\mathrm{HNO}_{3}$, the increase in adsorption capacity was still high; however, it did not exceed $30 \%$ (from 9.50 to $12.10 \mathrm{mg} / \mathrm{g}$ ). The affinity constant, $K_{\mathrm{L}}$, was the highest for $\mathrm{AC}-\mathrm{COOH}$, and its value was ca. 5-10 times greater than for carbon functionalised with sulphur-containing ligands. In these carbons, the $K_{\mathrm{L}}$ constant changed in the following order: AC-thiourea $>$ AC-cysteine $>$ AC-thiodiglycol. These findings show that thiourea, over the other studied ligands, has the highest affinity to bind $\mathrm{Cd}(\mathrm{II})$ ions.

\section{Factors influencing the adsorption of $\mathrm{Cd}(\mathrm{II})$}

The thermodynamic predictions showed that the $\mathrm{Cd}(\mathrm{II})$ ion is the only component in the $\mathrm{pH}$ range between 0 and 7. (Its relative abundance exceeded $99 \%$.) The adsorption studies were carried out at $\mathrm{pH} 7$. This value is higher than the point of zero charge of all the studied carbon adsorbents. Hence, their surface net charge is negative, and the electrostatic attraction of $\mathrm{Cd}(\mathrm{II})$ is possible. As shown in many previous works, the adsorption of $\mathrm{Cd}$ (II) (and other heavy metal cations) is generally driven by electrostatic interactions due to the presence of negatively charged surface acidic groups, which can compensate for the positive charge of Cd(II). Our findings are in agreement with these arguments. The surfaceoxidised carbons (and those subsequently functionalised with sulphur-containing ligands) had substantially better adsorption performance than the pristine material. This behaviour is unquestionably related to the presence of surface functionalities; however, the annealed AC showed a relatively high uptake of $\mathrm{Cd}(\mathrm{II})(4.52 \mathrm{mg} / \mathrm{g})$, although its surface acidity was very weak $(0.05 \mathrm{mmol} / \mathrm{g})$. It is highly likely that the adsorption of $\mathrm{Cd}(\mathrm{II})$ is a combination of two parallel and independent mechanisms. The first one is based on the compensation of electric charge on the negatively charged surface groups. The second mechanism likely involves noncovalent interactions with graphene layers, which can act as Lewis bases and form electron donor-acceptor complexes with positively charged $\mathrm{Cd}(\mathrm{II})$ ions. Note that $\mathrm{AC}$ is a highly disordered material, and does not have long-distance structural ordering. The high disorder implies that boundary hexagons in graphene layers may have a different charge density than 'internal' hexagons. This diversity realistically explains the observed uptake of $\mathrm{Cd}(\mathrm{II})$ onto annealed AC.

The presence of surface functional groups and sulphurcontaining ligands substantially improves the adsorption properties (Table 4). This prompts the question, "what is the quantitative impact of the surface acidic groups (and the attached ligands) on the uptake of Cd(II)?'. To start with, consideration of the background uptake of Cd(II) should be eliminated. This is an easy task because the annealed AC has a very low surface acidity, and its adsorption capacity $(4.52 \mathrm{mg} / \mathrm{g}$ ) can be used as the background value. Therefore, the reduced adsorption capacity can be calculated as being the experimental capacity diminished by the abovementioned background value. Next, one should be aware that at $\mathrm{pH} 7$, the electrostatic attraction of $\mathrm{Cd}(\mathrm{II})$ to the surface

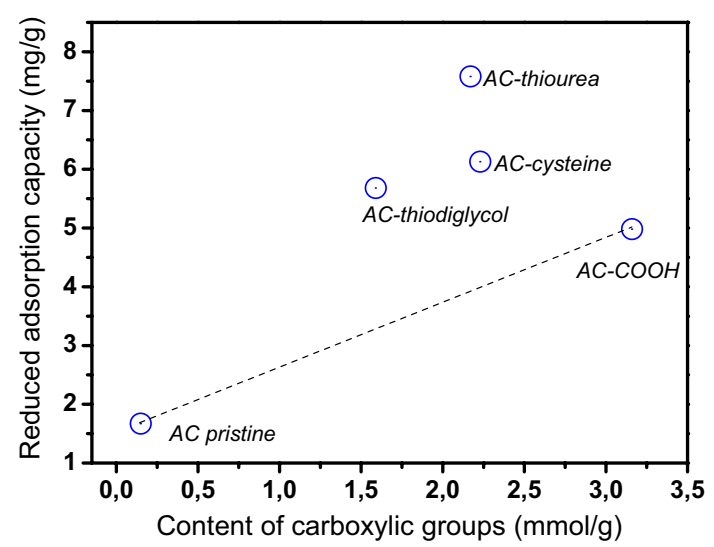

Fig. 7 Reduced adsorption capacity of $\mathrm{Cd}(\mathrm{II})$ in function of content of carboxylic groups 
occurs via carboxylic groups only. The lactone and phenol groups under this $\mathrm{pH}$ condition are neutral species. Figure 7 shows the relationship between reduced adsorption capacity and content of carboxylic groups. The dashed line connects the values for pristine and $\mathrm{HNO}_{3}$-oxidised carbons. The points that refer to the reduced adsorption capacity for carbon materials functionalised with sulphur-containing ligands are located above this straight line. This finding clearly demonstrates that the attached ligands must participate in the uptake of $\mathrm{Cd}(\mathrm{II})$. The enhanced adsorption capacity in ACcysteine and AC-thiourea is quite predictable, since the stable complexes of $\mathrm{Cd}(\mathrm{II})$ with these ligands are known from the literature (Zhou et al. 2015; Barragán et al. 2017; Jalilehvand et al. 2009). Surprisingly, the presence of thiodiglycol also facilitates the adsorption of $\mathrm{Cd}(\mathrm{II})$. The sulphur atom in thiodiglycol has a completely different chemical vicinity, i.e. it is bound to two methylene groups and located in the middle of the molecule. Nevertheless, thiodiglycol shows a moderate enhancement in the uptake of Cd(II).

The studied carbon materials had very distinct textural properties; for example, the specific surface area varied between $14 \mathrm{~m}^{2} / \mathrm{g}$ (AC-thiodiglycol) to $1083 \mathrm{~m}^{2} / \mathrm{g}$ (pristine $\mathrm{AC}$ ). A direct comparison of the textural properties with the maximum adsorption capacity did not provide a clear relationship between porosity and adsorption performance. This finding is in agreement with the opinion presented by Goyal et al. (2001).

The determined values of the point of zero charge (Table 3) can be used to predict the effect of $\mathrm{pH}$ on the adsorptive removal of $\mathrm{Cd}(\mathrm{II})$. The decrease in $\mathrm{pH}$ should lower the uptake of $\mathrm{Cd}$ (II). This is due to the protonation of the surface acidic groups and suppression of the electrostatic attractions between the negatively charged adsorbent surface and positively charged Cd(II) ions. This behaviour has been observed previously in surface-oxidised AC (Tang et al. 2017) and carbon cloth (Rangel-Mendez and Streat 2002). The uptake of $\mathrm{Cd}(\mathrm{II})$ at a $\mathrm{pH}$ below the point of zero charge should also be lower. Liu et al. (2008) demonstrated that the uptake of $\mathrm{Cd}$ (II) onto carbon nanotubes functionalised with L-cysteine under highly acidic conditions $(\mathrm{pH}=2)$ was substantially reduced. (The adsorption capacity was ca. 15 times lower compared to $\mathrm{pH}=7$.) On the other hand, increasing the $\mathrm{pH}$ to above 8 is associated with the precipitation of cadmium hydroxide ( $\mathrm{Li}$ et al. 2013). To conclude, the optimal $\mathrm{pH}$ for the adsorption of $\mathrm{Cd}(\mathrm{II})$ by $\mathrm{AC}$ functionalised with sulphur-containing ligands should be between 5 and 7 .

\section{Adsorption kinetics of $\mathrm{Cd}(\mathrm{II})$}

Figure 8 shows the adsorption kinetics curves, i.e. the relation between adsorption capacity and contact time. A brief look at the kinetics curves suggest the conclusion that the functionalised ACs are characterised by a faster adsorption
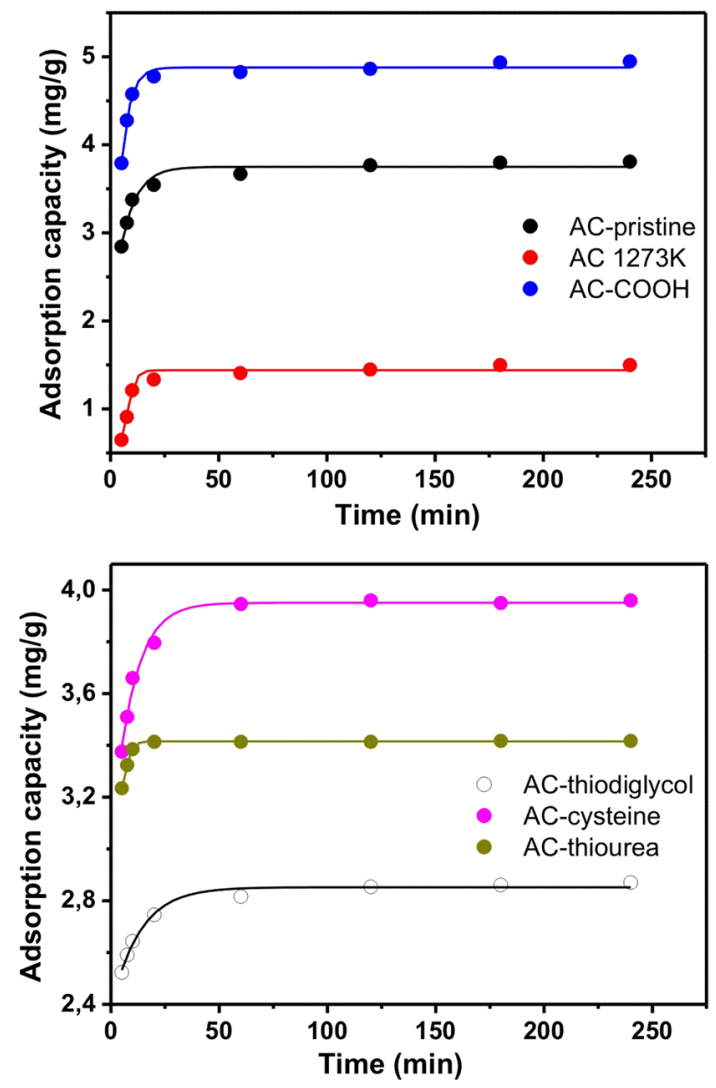

Fig. 8 Adsorption kinetics curves of Cd(II)

kinetics performance than pristine and annealed AC. Equilibrium was reached at a contact time of below $60 \mathrm{~min}$, and this observation is valid for each of the studied ACs. The uptake of Cd(II) after 5 min was greater than $85 \%$ for materials functionalised with sulphur-containing ligands. (100\% refers here to the uptake that is reached at equilibrium.) The uptake for the same contact time for the pristine material, AC-1273 and AC-COOH was 75\%, 29\% and 76\%, respectively. The reduction in adsorption kinetics rate for the annealed material was expected because similar findings were reported by Sato et al. (2007).

In order to compare the adsorption kinetics data in a quantitative way, a pseudo-second-order adsorption kinetics model was applied. The corresponding adsorption kinetics rates were evaluated from the linearised form of the model (Ho and McKay 1999). The obtained values are listed in Table 3. (The goodness of fit was greater than 0.98 in each case.) The adsorption kinetics rates for the pristine, annealed and $\mathrm{HNO}_{3}$-treated ACs were at a similar level, i.e. $0.141-0.152 \mathrm{~min}^{-1} \mathrm{mg}^{-1} \mathrm{~g}$. The introduction of thiodiglycol and cysteine doubled the kinetics rate (to $0.310-0.368 \mathrm{~min}^{-1} \mathrm{mg}^{-1} \mathrm{~g}$ ). The highest adsorption kinetics rate was found for AC functionalised with thiourea because, in this case, the rate was an order of magnitude 
higher than pristine $\mathrm{AC}, \mathrm{AC}-1273$ and $\mathrm{AC}-\mathrm{COOH}$. There was no correlation between the specific surface area and the obtained kinetics rates. This was especially evident for AC$\mathrm{COOH}$ and carbon functionalised with sulphur-containing ligands. These materials had comparable specific surface areas (Table 1); however, AC-thiodiglycol, AC-cysteine and AC-thiourea were characterised by at least a twice as fast adsorption process. This is likely related to the presence of sulphur-containing ligands.

\section{Conclusion}

Activated carbon was functionalised with three sulphurcontaining ligands-thiodiglycol, thiourea and cysteine. The functionalisation included pre-functionalisation in order to introduce surface acidic groups. The covalent binding of sulphur-containing ligands was achieved via amide or ester bonds. The surface-functionalised carbons had substantially lower porosity (10-15 times lower) than the pristine AC. The presence of introduced ligands was confirmed by FT-IR spectroscopy, elemental analysis and thermogravimetry. The content of ligands was between 8.8 and $14.7 \mathrm{wt} \%$, and the highest value was found for carbon functionalised with thiourea. All of the surface-functionalised ACs had an acidic character, and their point of zero charge was between 5.15 and 5.96. The chemical composition of the surface was tracked by Boehm titration. The content of acidic groups was the highest $(5.60 \mathrm{mmol} / \mathrm{g})$ for the $\mathrm{HNO}_{3}$-treated carbon. The surface acidity decreased after functionalisation with sulphur-containing ligands $(3.22-4.29 \mathrm{mmol} / \mathrm{g})$. It was found that the adsorption performance was strongly influenced by surface chemistry. The pre-functionalisation with $\mathrm{HNO}_{3}$ resulted in an increase in adsorption capacity from 6.19 to $9.50 \mathrm{mg} / \mathrm{g}$. A further increase in adsorption capacity was obtained after binding the sulphur-containing ligands, and the increase was observed for each ligand. The highest adsorption capacity was found for AC modified with thiourea. Finally, it was shown that the increase in the uptake of $\mathrm{Cd}(\mathrm{II})$ was directly related to the presence of sulphurcontaining ligands. The introduction of sulphur-containing ligands also improved the adsorption kinetics because the adsorption kinetics rates were an order of magnitude higher than in the pristine, annealed and $\mathrm{HNO}_{3}$-treated $\mathrm{AC}$.

Acknowledgments P. Pietrowski thanks the Central Institute of Labour Protection (Łódź, Poland) for low-temperature nitrogen adsorption measurements. Ajaya Bhattarai acknowledges the Erasmus Mundus fellowships for the Postdoctoral research work at the Faculty of Chemistry, University of Warsaw, Warsaw, Poland.

Open Access This article is distributed under the terms of the Creative Commons Attribution 4.0 International License (http://creat ivecommons.org/licenses/by/4.0/), which permits unrestricted use, distribution, and reproduction in any medium, provided you give appropriate credit to the original author(s) and the source, provide a link to the Creative Commons license, and indicate if changes were made.

\section{References}

Attar K, Bouazza D, Miloudi H, Tayeb A, Boos A, Sastre AM, Demey H (2018) Cadmium removal by a low-cost magadiite-based material: characterization and sorption applications. J Environ Chem Eng 6:5351-5360

Balbuena PB, Gubbins KE (1993) Theoretical interpretation of adsorption behavior of simple fluids in slit pores. Langmuir 99:1801-1814

Barragán P, Macedo MG, Olguín MT (2017) Cadmium sorption by sodium and thiourea-modified zeolite-rich tuffs. J Environ Sci (China) 52:39-48

Biniak S, Pakuła M, Świątkowski A, Bystrzejewski M, Błażewicz S (2010) Influence of high-temperature treatment of granular activated carbon on its structure and electrochemical behavior in aqueous electrolyte solution. J Mater Res 25:1617-1626

Boehm HP (2002) Surface oxides on carbon and their analysis: a critical assessment. Carbon 40:145-149

El-Bahy GMS, El-Sayed BA, Shabana AA (2003) Vibrational and electronic studies on some metal thiourea complexes. Vib Spectrosc 31:101-107

Faur-Brasquet C, Reddad Z, Kadirvelu K, Le Cloirec P (2002) Modeling the adsorption of metal ions $\left(\mathrm{Cu}^{2+}, \mathrm{Ni}^{2+}, \mathrm{Pb}^{2+}\right)$ onto ACCs using surface complexation models. Appl Surf Sci 196:356-365

Fernandez MA, Sanz P, Palomar M, Serra J, Gadea E (1996) Fatal chemical pneumonitis due to cadmium fumes. Occup Med 46:372-374

Gao J, Sun SP, Zhu WP, Chung TS (2016) Green modification of outer selective P84 nanofiltration (NF) hollow fiber membranes for cadmium removal. J Membr Sci 499:361-369

Ghanemi K, Nikpour Y, Omidvar O, Maryamabadi A (2011) Sulfurnanoparticle-based method for separation and preconcentration of some heavy metals in marine samples prior to flame atomic absorption spectrometry determination. Talanta 85:763-769

Göde C, Lütfi Yola M, Yılmaz A, Atar N, Wang S (2017) A novel electrochemical sensor based on calixarene functionalized reduced graphene oxide: application to simultaneous determination of $\mathrm{Fe}(\mathrm{III}), \mathrm{Cd}(\mathrm{II})$ and $\mathrm{Pb}(\mathrm{II})$ ions. J Colloid Interface Sci 508:525-531

Goyal M, Rattan VK, Aggarwal D, Bansal RC (2001) Removal of copper from aqueous solutions by adsorption on activated carbons. Colloids Surf A 190:229-238

Gupta VK, Lütfi Yola M, Atar N, Ustundağ Z, Solak AO (2013) A novel sensitive $\mathrm{Cu}(\mathrm{II})$ and $\mathrm{Cd}(\mathrm{II})$ nanosensor platform: graphene oxide terminated p-aminophenyl modified glassy carbon surface. Electrochim Acta 112:541-548

Harris PJF, Liu Z, Suenaga K (2008) Imaging the atomic structure of activated carbon. J Phys: Condens Matter 20:362201

Hartwig A (2013) Cadmium and cancer. Met Ions Life Sci 11:491-507

Ho YS, McKay G (1999) Pseudo-second order model for sorption processes. Proc Biochem 34:451-465

Huang X, Gao N, Zhang QL (2007) Thermodynamics and kinetics of cadmium adsorption onto oxidized granular activated carbon. $\mathrm{J}$ Environ Sci 19:1287-1292

Huang L, Yuan S, Lv L, Tan G, Liang B, Pehkonen SO (2013) Poly(methacrylic acid)-grafted chitosan microspheres via surfaceinitiated ATRP for enhanced removal of $\mathrm{Cd}$ (II) ions from aqueous solution. J Colloid Interface Sci 405:171-182 
Islamoglu S, Yilmaz L, Ozbelge HO (2006) Development of a precipitation based separation scheme for selective removal and recovery of heavy metals from cadmium rich electroplating industry effluents. Sep Sci Technol 41(15):3367-3385

Izidoro JC, Fungaro DA, Abbot JE, Wang S (2013) Synthesis of zeolites $\mathrm{X}$ and $\mathrm{A}$ from fly ashes for cadmium and zinc removal from aqueous solutions in single and binary ion systems. Fuel 103:827-834

Jalihenvand F, Leung BO, Mah V (2009) Cadmium(II) complex formation with cysteine and penicillamine. Inorg Chem 48:5758-5771

Jalilehvand F, Mah V, Leung BO, Mink J, Bernard GM, Hajba L (2009) Cadmium(II) cysteine complexes in the solid state: a multispectroscopic study. Inorg Chem 48(9):4219-4230

Kheriji J, Tabassi D, Hamrouni B (2015) Removal of Cd(II) ions from aqueous solution and industrial effluent using reverse osmosis and nanofiltration membranes. Water Sci Technol 72(7):1206-1216

Li Y, Mei K, Poon Y, Monash P, Ibrahim S, Saravanan P (2013) Surface chemistry and adsorption mechanism of cadmium ion on activated carbon derived from Garcinia mangostana shell. Korean J Chem Eng 30(10):1904-1910

Lind Y, Engman J, Jorhem L, Glynn AW (1997) Cadmium accumulation in liver and kidney of mice exposed to the same weekly cadmium dose continuously or once a week. Food Chem Toxicol 35:891-895

Lin-Vien D, Colthup NB, Fateley WG, Grasselli JG (1991) The handbook of infrared and raman characteristic frequencies of organic molecules. Academic Press Ltd, London, p 235

Liu Y, Li Y, Yan XP (2008) Preparation, characterization, and application of L-cysteine functionalized multiwalled carbon nanotubes as a selective sorbent for separation and preconcentration of heavy metals. Adv Funct Mater 18:1536-1543

Liu S, Li Z, Wang C, Jiao A (2016) Enhancing both removal efficiency and permeate flux by potassium sodium tartrate (PST) in a nanofiltration process for the treatment of wastewater containing cadmium and zinc. Sep Purif Technol 116:131-136

Lütfi Yola M, Eren T, İlkimen H, Atar N, Yenikaya C (2014) A sensitive voltammetric sensor for determination of $\mathrm{Cd}(\mathrm{II})$ in human plasma. J Mol Liq 197:58-64

Machida M, Fotoohi B, Amamo Y, Mercier L (2012) Cadmium(II) and lead(II) adsorption onto hetero-atom functional mesoporous silica and activated carbon. Appl Surf Sci 258:7389-7394

Moreno-Castilla C, Lopez-Ramon MV, Carrasco-Marin F (2000) Changes in surface chemistry of activated carbons by wet oxidation. Carbon 38:1995-2001

Noh JS, Shwarz JA (1990) Effect of HNO3 treatment on the surface acidity of activated carbons. Carbon 28:675-682

Pakuła M, Świątkowski A, Walczyk M, Biniak S (2005) Voltammetric and FT-IR studies of modified activated carbon systems with phenol, 4-chlorophenol or 1,4-benzoquinone adsorbed from aqueous electrolyte solutions. Colloids Surf A 260:145-155

Pirsaheb M, Sharafie K, Naderi S, Ghafari HR, Khosravi T (2017) Role of reverse osmosis membranes on the concentration fluctuations of heavy metals in used water by dialysis instrument of hemodialysis patients. Ann Trop Med Public Health 10(4):1019-1023

Pyrzyńska K (2010) Sorption of Cd(II) onto carbon-based materials-a comparative study. Microchim Acta 169:7-13

Radovic LR, Moreno-Castilla C, Rivera-Utrilla J (2001) Carbon materials as adsorbents in aqueous solutions. In: Radovic LR (ed) Chemistry and physics of carbon, vol 27. Marcel Dekker, New York, pp 227-406

Rangel-Mendez JR, Streat M (2002) Adsorption of cadmium by activated carbon cloth: influence of surface oxidation and solution pH. Water Res 36:1244-1252

Rodríguez-Estupiñana P, Giraldoa L, Moreno-Piraján JC (2013) Energetic changes in the surface of activated carbons and relationship with Ni(II) adsorption from aqueous solution. Appl Surf Sci 286:351-357

Saljoughi E, Mousavi SM (2013) Preparation and characterization of novel polysulfone nanofiltration membranes for removal of cadmium from contaminated water. Sep Purif Technol 90:22-30

Sato S, Yoshihara K, Moriyama K, Machida M, Tatsumoto H (2007) Influence of activated carbon surface acidity on adsorption of heavy metal ions and aromatics from aqueous solution. Appl Surf Sci 20:8554-8567

Socrates G (2001) Infrared and Raman characteristic group frequencies: tables and charts. Wiley, Hoboken, p 126

Sukreeyapongse O, Holm PE, Strobel BW, Panichsakpatana S, Magid J, Hansen HCB (2002) pH dependent release of cadmium, copper, and lead from natural and sludge-amended soils. J Environ Qual 31:1901-1909

Tan H, He W, Han H, Zheng C, Ma Y, Chen Y, Bu J (2013) Cadmium removal in water emergency treatment of conventional process enhanced by chemical precipitation. Chin J Environ Eng $7(3): 848-852$

Tang C, Shu Y, Zhang R, Li X, Song J, Li B, Zhang Y, Oua D (2017) Comparison of the removal and adsorption mechanisms of cadmium and lead from aqueous solution by activated carbons prepared from Typha angustifolia and Salix matsudana. RSC Adv 7:16092-16103

Youssef AM, El-Nabarawy Th, Samra SE (2004) Sorption properties of chemically-activated carbons: 1 . Sorption of cadmium(II) ions. Colloids Surf A 235:153-163

Zhou Y, Xia XM, Lingle CJ (2015) Cadmium-cysteine coordination in the BK inner pore region and its structural and functional implications. Proc Natl Acad Sci USA 112(16):5237-5242 